\title{
ГИДРОХИМИЧЕСКИЕ ПОКАЗАТЕЛИ ЭКОЛОГИЧЕСКОГО СОСТОЯНИЯ СТАРИЧНЫХ ВОДОЕМОВ СРЕДНЕГО ТЕЧЕНИЯ РЕКИ ДОН В ПРЕДЕЛАХ ВОРОНЕЖСКОЙ ОБЛАСТИ
}

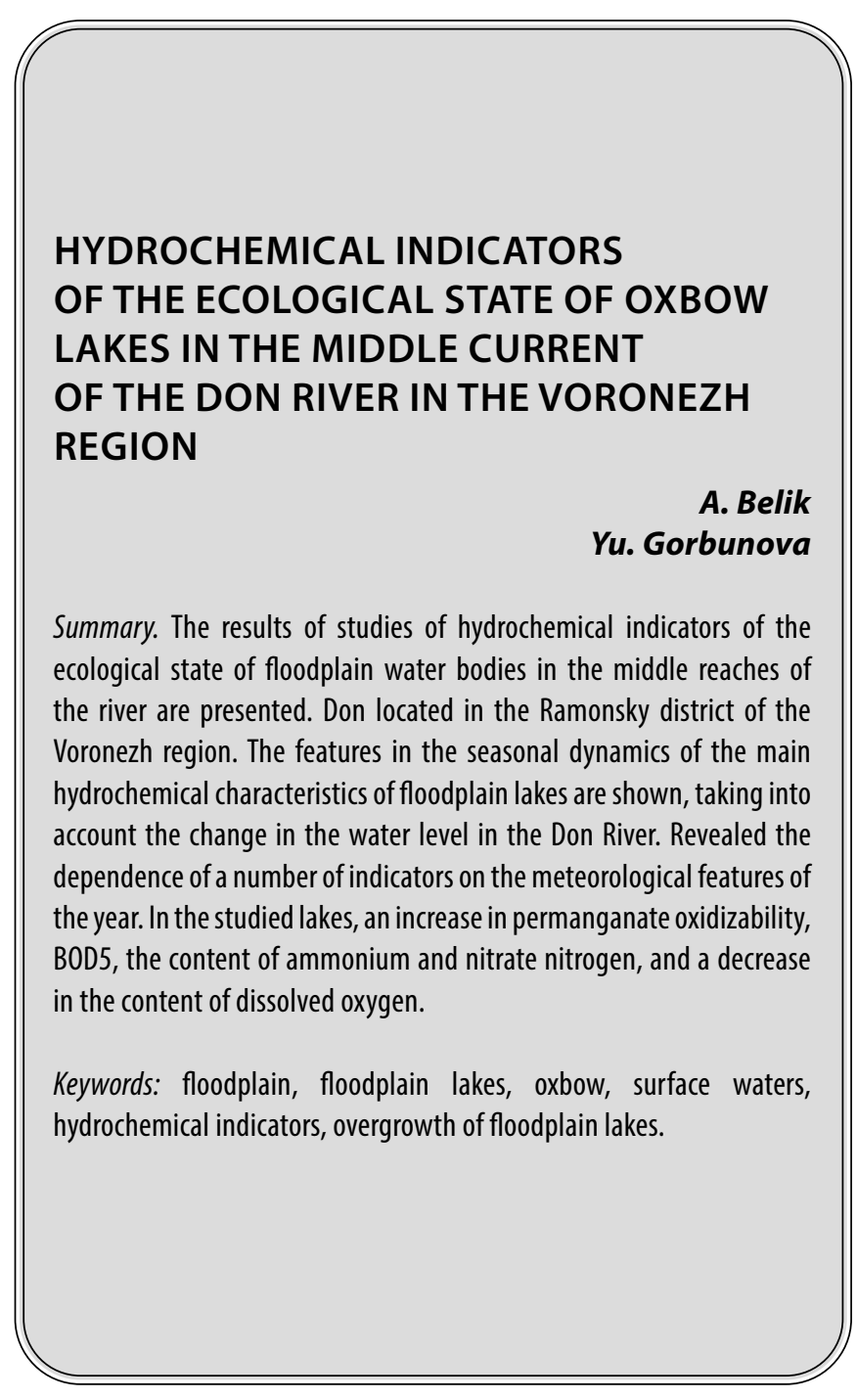

\section{Введение}

P ечные поймы традиционно принято характеризовать как слабо устойчивые к воздействию человека природные системы. Периодическое затопление поймы в сочетании с особенностями микроклимата создают благоприятные условия для загрязнения ее биогенными элементами и поллютантами [2, 3, 5-7]. Необходимо отметить, что нередко пойменные ландшафты активно используются человеком, как в сельскохозяйственном производстве, так и в рекреационной деятельности и для них харак-
Белик Антон Викторович

К.б.н., дочент, Воронежский государственный

университет

abelik36@gmail.com

Горбунова Юлия Сергеевна

К.б.н., дочент, Воронежский государственный университет

gorbunova.vsu@mail.ru

Аннотация. Представлены результаты исследований гидрохимических показателей экологического состояния пойменных водоемов среднего течения р. Дон, расположенных в Рамонском районе Воронежской области. Показаны особенности сезонной динамики основных гидрохимических характеристик пойменных озер с учетом изменения уровня воды в реке Дон. Выявлена зависимость ряда показателей от метеорологических особенностей года. В исследованных озерах отмечено повышение перманганатной окисляемости, БПК5, содержания аммонийного и нитратного азота и снижение содержания растворенного кислорода.

Ключевые слова: пойма, пойменные озера, старица, поверхностные воды, гидрохимические показатели, зарастание пойменных озер.

терным является активное развитие деградационных процессов [1, 7]

Одним из потенциальных комплексных индикаторов, по которому можно делать определенные выводы о состоянии речной поймы является наличие и функционирование старичных водоемов. Они, вместе с почвенным покровом выступают как специфический фильтр загрязняющих веществ, поступающих с поверхностным и внутрипочвенным стоком с водоразделов, сохраняя при этом связи с подземными и грунтовыми водами. Как следствие они в значительной степени из- 
меняют микроклиматические условия и гидрологический баланс территории, в пределах которой эти водоемы располагаются [2, 3, 11-12].

В условиях Воронежской области пойменные озера, характерные для наиболее крупных рек: Дон, Воронеж, Битюг, Хопер, испытывают очень серьезное антропогенное давление, связанное с хозяйственной и рекреационной деятельностью [1, 5-8, 12].

Цель данной работы заключается в исследовании сезонной динамики наиболее значимых гидрохимических характеристик старичных озер Рамонского района Воронежской области: Стрелецкое, Кужное, Круглое, находящихся на небольшом расстоянии друг от друга и некогда формировавших русло реки Дон.

\section{Объекты и метолы исслеАования}

Гидрохимические исследования пойменных водоемов проводилось в осенью 2016 и весной 2017 гг. Это позволило рассмотреть динамику гидрохимических характеристик водоемов в период летне-осенней межени и в период весеннего половодья. Объектами исследования являются старичные озера, расположенные в пойме реки Дон: Стрелецкое, Кужное, Круглое. Все обследованные озера по морфометрической классификации относятся к очень малым [9].

Отбор проб, осуществлялся исходя из требований государственного стандарта «ГОСТ 31861-2012 Вода. Общие требования к отбору проб» [4]. Последующий лабораторный анализ гидрохимических показателей осуществлялся по стандартным лабораторным методикам. В отобранных пробах определялись: $\mathrm{pH}$ - потенциометрическим методом, содержание растворенного кислорода и БПК по Винклеру, перманганатная окисляемость - титриметрическим методом, общая жесткость, содержание ионов калиция и магния - комплексонометрически, сульфат-ионы - турбидиметрическим методом, хлорид-ионы - аргентометрическим методом, общее железо, нитрат- и нитрит-ионы - фотоколориметрически. Сухой остаток определялся гравиметрически [10].

Озеро Стрелецкое находится на западе Рамонского района, вблизи села Медовка. Длина его составляет 780 м, площадь - 14598 м² (0,015 км²). Средняя глубина озера - около 1,0 м в меженный период. Озеро имеет вытянутую с севера на юг форму, характерную для старичных водоемов. Озеро активно используется для рекреации, активно очищается и поэтому процессы зарастания в значительной степени заторможены.

Озеро Кужное расположено на юго-западе Рамонского района вблизи села Новоподклетное. Озеро распо- ложено в 10,7 км к югу относительно озера Стрелецкое.

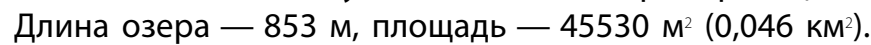
Озеро имеет дугообразную форму с сужением в южной части, вызванной интенсивным зарастанием. Средняя глубина озера составляет 1,5 м в меженный период.

Озеро Круглое расположено в микрорайоне Подгорное городского округа г. Воронеж в 2,1 км южнее озера Кужное. Ранее территория, на которой расположено озеро административно относилась к Рамонскому и Семилукскому районам Воронежско области. Дли-

на озера составляет 7004 м, Общая площадь - 67030 м²

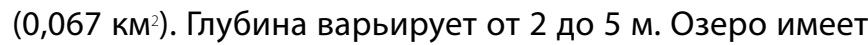
хорошо выраженную дугообразную форму, В центральной части озера имеется плотина, делящая озеро на две половины: северную и южную.

Осенью 2016 года была предпринята незаконная попытка осушить озеро Круглое. В результате к моменту прекращения работ средний уровень воды в озере в среднем снизился на 1 м. Экосистемам поймы реки Дон и непосредственно самой реке был нанесен существенный ущерб. В 2018 году озеру Круглое и территории к нему прилегающей был придан статус памятника природы регионального значения.

\section{Результаты и обсужление}

Проведенный лабораторный анализ объектов исследования показал, что по большинству основных гидрохимических показателей в нормативные значения предельно допустимых концентраций не превышаются. В то же время различная степень зарастания озер в сочетании с метеорологическими условиями и уровнем антропогенного воздействия определило своеобразие динамики гидрохимических показателей.

В осенний период значения $\mathrm{pH}$ на всех объектах мало отличались между собой (табл. 1), по-видимому, повышение $\mathrm{pH}$ связано было с ростом общей жесткости и минерализацией в летне-осенний сухой период.

При этом в наибольшей степени этот показатель снижался на наименее заросшем Стрелецком озере (падение составило 0,9), а в наименьшей степени на заросшем озере Кужном (с 7,7 до 7,5). В значительной степени стабильность этого показателя в случае Кужного определяется интенсивным поступлением органических соединений в половодье с сельскохозяйственных угодий и значительным поверхностным стоком с надпойменной террасы при снеготаянии.

С показателем кислотности тесно связана общая жесткость воды и содержание ионов кальция и маг- 
Таблица 1. Результаты химического анализа за период осень-весна

\begin{tabular}{l|l|l|l|l|l|l|l|} 
Название \\
объекта
\end{tabular}

ния. Озера характеризуются в осенний период варьированием общей жесткости в интервале 7,0-8,3 мг-экв/ дм³ $^{3}$ Весной этот показатель на всех объектах снизился в 2,7-6 раз.

В первую очередь это связано с тем, что лето 2016 года отличалось засушливостью, обусловившим подтягивание к поверхности минерализованных грунтовых вод и повышением испарения с поверхности водных объектов, что вызвало концентрирование содержащихся в воде соединений кальция и магния. Весной вследствие снеготаяния произошло разбавление и снижение общей жесткости в 2-5 раз. Наибольшей жесткостью воды отличались озера с достаточно слабо выраженным зарастанием (Стрелецкое и Круглое) и сохранившие связь с грунтовыми водами в качестве источников, подпитывающих водоемы (табл. 1). Весной максимальная жесткость была характерна для озера Кужное - 3,0 мг-экв/дм³. В данном случае, по-видимому, жесткость в большей степени формировалась за счет поступления кальция и магния при с поверхностным стоком и в результате таяния снега.

По сезонной динамике жесткости и содержания ионов кальция и магния выявлены сходные тенденции. В осенний период наблюдается резкий рост концентрации кальция и магния, в весенний - отмечено резкое снижение (табл. 1).

Наиболее представительными гидрохимическими характеристиками вод пойменных водоемов следует признать содержание растворенного кислорода в воде, биохимическое потребление кислорода за 5 суток и перманганатную окисляемость.
Последняя характеризует интенсивность протекания процессов окисления органических веществ, рост концентрации которых в пойменных озерах связан с их зарастанием. В осенний период отмечается снижение окисляемости от наиболее чистого к наиболее заросшему озерам (от 2,6 до 1,8 мг О яснить тем, что на Стрелецком и Круглом озерах идет весьма интенсивный процесс эвтрофикации, тогда как на озере Кужное достигнут определенный баланс между поступлением и разложением органических веществ. Весной наблюдалась обратная картина (максимальная величина окисляемости была характерна для озера Кужное, с незначительным снижением в воде Стрелецкого и Круглого озер).

По содержанию растворенного кислорода следует отметить, что в осенний период на всех озерах наблюдалось минимальное содержание кислорода, связанное с жарким летним периодом и интенсивным поступлением органических веществ. Общее содержание растворенного кислорода в обследованных объектах осенью было в 2-3 раза установленных нормативах ПДК для водоемов рыбохозяйственного назначения (от 2,4 до 2,9 мг/дм³). В весенний период наблюдался резкий рост этого показателя (в 4-5 раз). Это связано с поступлением в водоемы снеговых вод, которые перенасыщены кислородом. При этом минимальное содержание растворенного кислорода наблюдалась наиболее заросшем озере Кужном - 10,7 мг/дм³, а максимальная величина на озере Круглое - 21,6 мг/д.

Похожая тенденция характерна и для сезонной динамики БПК ${ }_{5}$. Максимальные значения этого показателя наблюдалось на озере Круглом и озере Стрелецком, 
что подтверждалось визуально замором рыбы, на фоне явного дефицита растворенного кислорода в воде. Весной этот показатель закономерно возрастал в зависимости от степени зарастания, но при этом этот рост составил всего 1-2 мг/дм³ (табл. 1).

В исследуемых водоемах не было обнаружено превышения ПДК по хлоридам и сульфатам. В весенний период, после половодья количество хлоридов несколько выше (от 12,4 до 15,4 мг/дм³), по сравнению с летне-осенней меженью, когда содержание хлоридов в воде объектов исследования изменялось от 1,7 до 9,4 мг/дм

Содержание сульфатов в обследованных водоемах невелико (от 0,6 до 11,5 мг/дм³). Незначительное их увеличение приходится на весенний период, когда происходит снеготаяние, поскольку сульфат-ионы накапливаются в снеге за счет осаждения аэрозолей диоксида серы из воздуха вместе с пылью.

По содержанию железа норматив ПДК превышен во всех объектах исследования в осенний период (в среднем в 1,5 раза), что связано с динамикой содержания растворенного кислорода, поступлением и накоплением в воде органических растительных остатков. В весенний период наблюдается превышение ПДК только для Стрелецкого (в 1,5 раза).

Важными показателями, по которым можно судить о интенсивности зарастания озер, наряду с БПК, перманганатной окисляемостью и растворенным кислородом является содержание аммонийного и нитратного азота. Максимальные концентрации аммонийных ионов наблюдались осенью, в момент, когда шло интенсивное разложение органических веществ. При этом максимальное содержание аммонийного азота наблюдалось в озере Стрелецком (почти достигая значения ПДК), что свидетельствует об интенсификации процес- сов зарастания на этом водоеме. Далее идет заросшее озеро Кужное и озеро Круглое (табл. 1).

В весенний период концентрация ионов аммония резко снижается, что связано с разбавлением в результате снеготаянием и торможением биохимических процессов в зимнее время.

По содержанию нитратного азота следует отметить, что для озер Стрелецкое (36,0 мг/M³) и Кужное (25,0 мг/ $\mathbf{M}^{3}$ ) характерно увеличение их содержания весной по сравнению с осенью (28,0 и 21,0 мг/дм³ соответственно), а для Круглого снижение (25 мг/дм³).

\section{Зак^ючение}

Пойменные водоемы являются важным элементом пойменных ландшафтов, осуществляющие функции регулирования микроклимата, гидрологического режима и продуктивности пойменных экосистем, при этом нередко являющиеся объектами рекреационного и хозяйственного использование.

Зарастание этих водоемов является по сути своей естественным процессом, в условиях антропогенного воздействия приобретает значительное ускорение, что отражается в целом на функционировании пойменного ландшафта.

Озера Стрелецкое, Круглое и Кужное, характеризуются различной степенью зарастания и различным использованием. В целом для этих водоемов характерно удовлетворительное состояние. В то же время для них, особенно для озера Стрелецкое, в осенний период характерен заметный рост перманганатной окисляемости, БПК ${ }_{5}$, содержания аммонийного и нитратного азота и снижение содержания растворенного кислорода свидетельствует об активном развитии процессов зарастания.

\section{ЛИТЕРАТУРА}

1. Атлас-книга Воронежской области / под ред. Федотова. - Воронеж: Изд-во ВГУ, 2013. - 514с.

2. Барышников Н.Б. Морфология, гидрология и гидравлика пойм / Н.Б. Барышников. - М.: Гидрометеоиздат, 1984. - 280 с.

3. Баянов Н.Г. Межсезонная динамика гидролого-гидрохимических показателей реки Керженец и ее стариц / Н.Г. Баянов, Т.В. Кривдина // Известия РАН. Серия географическая. - 2013.- № 2.- C. 52-67.

4. ГОСТ 31861-2012 Вода. 0бщие требования к отбору проб. Утвержден и введен в действие Приказом Федерального агентства по техническому регулированию и метрологии от 29 ноября 2012. N1513-ст. Дата введения — 1 января 2014 г. URL: https://docs.cntd.ru/document/1200097520?section=0p erative (дата обращения: 20.06.2021). - Текст: электронный.

5. Дмитриева В.А. Гидрологическая изученность Воронежской области. Каталог водотоков / В.А. Дмитриева. — Воронеж: ИПЦ ВГУ, 2008. — 225 с

6. Дмитриева В.А. Гидрологическая роль озер и болот воронежской области/ Дмитриева В.А.// Вестн. Воронеж. гос. ун-та. Сер. География. Геоэкология. - 2010. — № 1.— С. 98-101.

7. Добровольский Г.В. Поймы рек как ландшафты высокой плотности жизни и интенсивного почвообразовательного процесса / Г.В. Добровольский // Биологическая продуктивность и круговорот химических элементов в растительных сообществах: сборник статей.— Л., 1971.—C. 226-231. 
8. Курдов А.Г. Гидрологические районы центрально-черноземных областей // Науч. основы рационального использования почв Черноземной зоны СССР и повышение их плодородия. Воронеж, 1966. Вып. 2. С. 103-106.

9. Мякишева Н.В. Многокритериальная классификация озер /Н.В. Мякишева. - СПб.: изд. РГГМУ, 2009. — 160 с.

10. Аналитический контроль окружающей среды: учебно-методическое пособие. Ч. 1. Вода / Е.А. Негробова, Л.А. Алаева, А.В. Белик. - Воронеж: Издательский дом ВГУ, 2020.- 102 с.

11. Петрова Е.А. Особенности зарастания озер-стариц реки Суры // Вестник Чувашского государственного педагогического университета им. И.Я. Яковлева. — 2009. — № 3-4. -С. 77-83.

12. Печенюк Е.В. Динамика зарастания пойменных озер в Хоперском государственном заповеднике // Ботан. журн. - 1986. - Т. 71. -С. 637-642.

( ) Белик Антон Викторович ( abelik36@gmail.com ), Горбунова Юлия Сергеевна ( gorbunova.vsu@mail.ru ).

Журнал «Современная наука: актуальные проблемы теории и практики»

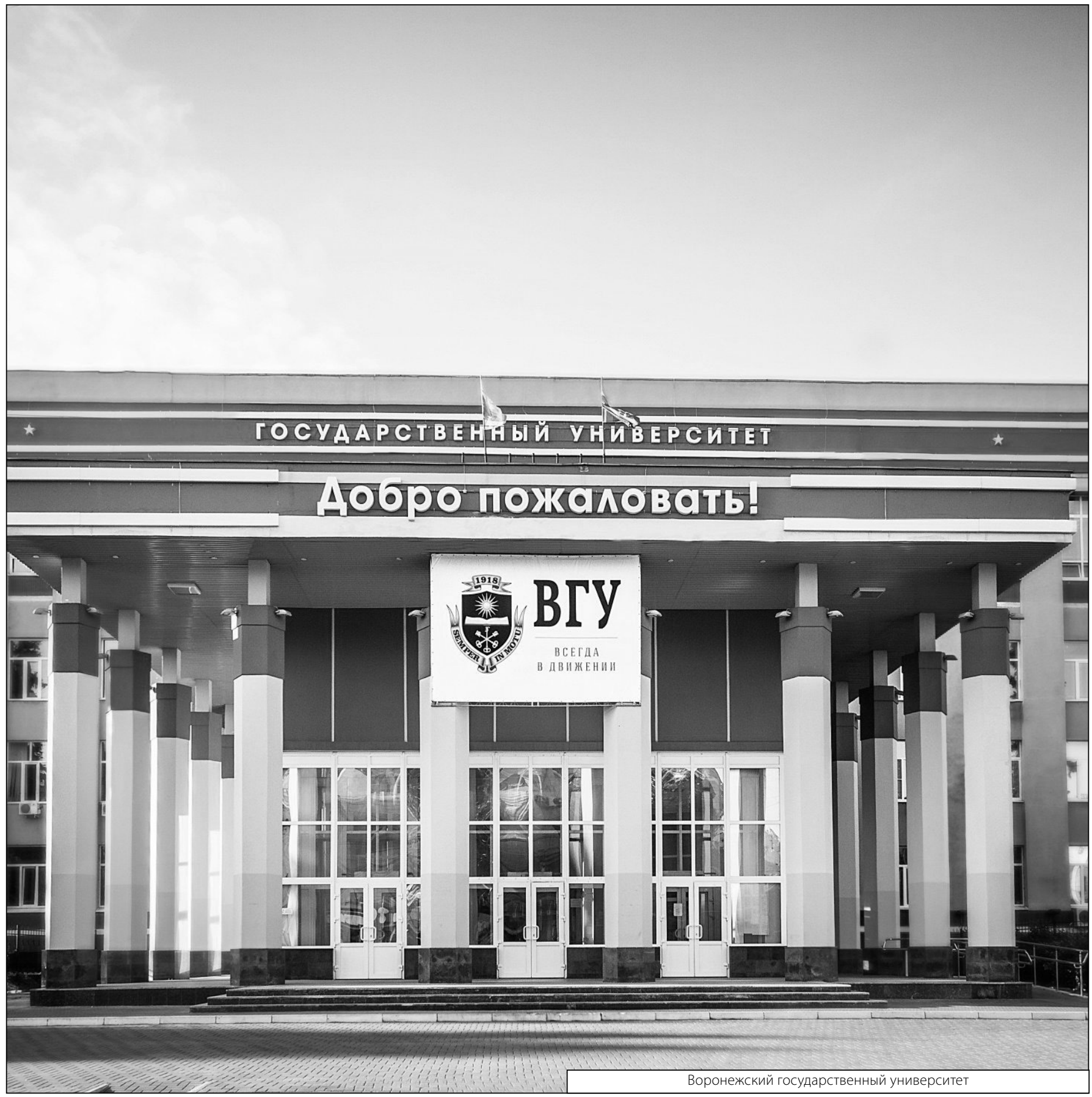

